\title{
Research on Pushing the Individualized Online Learning Resources for College Students
}

\author{
Qian Yan ${ }^{1, a}$, Qian Shuang ${ }^{2, b}$ \\ ${ }^{1}$ Baicheng Normal College, Media Institute, Baicheng, Jilin \\ ${ }^{2}$ Jiutai District 31st Middle School, Changchun, Jilin \\ aqianyan1982@126.com, bakzx0001@126.com
}

Keywords: University students; Links; Clustering; Knowledge points

\begin{abstract}
Education has ushered in the third great change in human history, and meeting the individual learning needs of each learner has become the main content of this educational change. Personalized learning promotes students to maximize their individual potential and meets the needs of current college personnel training. With the development of information technology, the internationalization of online learning content in China is becoming more and more obvious. It is the mission of online education in the information age to use the Internet and digital innovative technology to customize each student's own personalized learning resources. However, students 'personalized online learning faces many problems: the contradiction between massive online resources and college students' indiscriminate blind search; The inefficient use of these resources results in a waste of resources; It does not really realize the vision of customization, interactive learning, and so on. Based on the relevant theoretical foundation, we build a personalized online learning resource push model for college students.
\end{abstract}

\section{Introduction}

With the increasing globalization of educational technology, the internationalization of online learning content in China has become more and more obvious. Many Chinese students will participate in online learning with students from around the world and experience the advantages of online learning in terms of interactivity, participation and richness. In the context of globalization, the use of information technology to promote education reform is a necessary road, and information learning is a process based on the Internet to promote the combination of high-quality resources at home and abroad to learners.

In the vision of modern education, everyone is different, with their own unique interests, hobbies and learning needs. Personalized learning is to pay attention to and explore each student's unique endowment. Education in the Internet era breaks through the limitations of schools and classrooms. Through online learning, students can adopt unique learning paths, learning methods and learning strategies according to their own characteristics and needs, thus effectively promoting individual development and self-realization. This is the real picture of lifelong education and learning society that is emerging in the Internet era. With the popularization of network technology, the cost effectiveness of network hardware equipment and mobile terminal equipment is becoming more and more high, providing material guarantee for the development of personalized learning. In short, online resources are an important channel for college students to acquire knowledge and expand their horizons. It is the general trend of university teaching reform to apply various methods to carry out individualized learning.

\section{Definition of Relevant Concepts}

\subsection{Online learning resources}

In the context of the rapid development of information technology, the ways and means of knowledge acquisition have undergone great changes. The traditional classroom teaching 
environment has gradually integrated into the network environment. We use various computer teaching software to present and beautify the teaching content, and make, publish, and share rich teaching resources. With the rapid development of a new generation of information technology such as computer, electronic technology and network communication technology, a new type of electronic learning resource, namely online learning resources, has emerged in the online learning environment. In general, online learning resources refer to various information resources for teaching and learning activities that can be operated in a multimedia computer or network environment after digital processing. Online learning resources are based on traditional learning resources, but they also give new characteristics, expand the connotation and extension of knowledge, improve teaching methods, improve teaching results, and are conducive to cultivating learners 'ability to learn independently.

\subsection{Resource push model}

Resource push model is a process flowchart that shows resource demand, resource push and resource feedback. The resource push model of this paper is to meet the requirements of university students to learn diversity, use large data, cloud computing and other technologies, effectively integrate a huge information database, and use related information technology means to build information resource push mode that is easy for college students to find and use. Based on the analysis of learners 'characteristics and resources' characteristics, resource push is carried out to provide learners with individualized learning resources based on the principle of association clustering. The characteristics of the resource push model in this study are: the resource is well-targeted, and the push method is diversified.

\section{Relevant Theoretical Basis}

\subsection{Connectivism Learning Theory}

The communicative learning concept holds that the ability to do things and the method of learning are more important than knowledge itself. Pipeline is far more important than content. Connectivism learning must meet two basic conditions: First, learners have received education and have the confidence and ability to use the Internet to learn. Secondly, learners can judge the authenticity and correctness of information. Learners need to master the methods and ways of choosing, processing, filtering knowledge, and picking key points in order to obtain the knowledge content they need.

In the construction and application of resource push models for college students, based on the principle of related clustering, a two-feature model of "learner-resource" is constructed, and there is a connection between learners and others. There is a link between resources and other resources, and between learners and resources. In these one-to-many relationships, individual network resources and other social network resources interact and communicate with each other. Individuals can transmit resources for sharing by others, that is, upload. Each learner can also actively download resources. In the complex information network environment, how to effectively push resources out, we want to send personalized resources to college students must be oriented. It is necessary to analyze the college students 'majors, interests, and learning needs in detail, and through research, understand the current situation and needs of college students' online resources delivery, and push different types of resources to different users in different ways, so as to achieve individual push. Enable learners to achieve efficient learning.

\subsection{Multiple Intelligence Theory}

The theory of multiple intelligence holds that human intelligence is diverse and consists of nine kinds of intelligence such as language, logic, space, sports, music, interpersonal, introspection, natural exploration, and survival. There are differences in the intellectual composition of different individuals. In the process of teaching, it is advocated that "student-centered" should be used to carry out teaching activities. Gardner emphasizes the plasticity, flexibility, and diversity of 
intelligence. He believes that intelligence depends on the potential or tendency that has been recognized or not yet recognized in the individual's cultural background. This potential or tendency is the ability to solve problems or produce products in a specific cultural or social environment. This kind of intelligence is formed by the individual's growth, development and mature construction of internal cognition and external cognition. The theory of multiple intelligence believes that evaluating students should be evaluated in one aspect. Because of the differences in individual intelligence and characteristics, their learning methods are different. Because of the diversity of intelligence, the evaluation of student learning should be participated by many people, and the content and method of evaluation should also reflect diversity. The personalized online resource delivery for college students emphasizes the importance of individual students, multiple intelligence, and independent selection. Therefore, the courses selected for students should involve a wide range, rich content, and diverse types. Students can consciously explore, discover, and develop their own intellectual potential according to their own interests. In the process of online resource delivery, attention should be paid to the design of the learning environment, interactive communication, evaluation feedback, etc., the understanding and extension of knowledge, and the conscious cultivation of students 'independent thinking ability and the ability to solve problems in life practice.

\subsection{Humanism Theory}

Humanistic theory emerged in the United States in the 1950s and 1960s. The theory holds that in the process of education and teaching, the learner's own position and meaning should be used to describe learning, not the position of others. Research on how to create a good environment for learners to perceive the world from their own perspective, understand the world, understand the world, and reach the highest level of self-realization. The purpose of humanism is to pay attention not only to the development of cognition in teaching, but also to the development of the emotions, interests, and motives of middle school students in teaching, and to pay attention to the understanding of the students 'inner psychological world in order to meet the students' interests, needs, experiences, and personality differences. To develop students 'potential, stimulate the interaction between cognition and emotion, and attach importance to the psychological aspects of creativity, cognition, motivation, and emotion to restrict behavior. Humanism learning theory pays attention to the main position of people in learning activities, putting respect for people, understanding people, and believing people first in education. In the design of personalized resource delivery for college students, we must pay attention to the study of the college students as a group, because all resources, environments, methods, technologies, etc. are for learners. In the design of resource push, we should give full consideration to the current situation and needs of college students 'personalized online learning. Humanistic learning theory emphasizes the all-round development of human beings and emphasizes self-development in the learning process. In the personalized online resource delivery for college students, we should focus on the "center" of students to elaborate the design of each link. Ensure the initiative and enthusiasm in the process of discussion and communication so that college students can realize their sense of self-existence.

\section{Construction of Online Learning Resource Push Model for College Students}

\subsection{The Design Concept of the Model}

The design principles of the model are as follows:

Relevance: Association is the export of interrelationships between data. Clustering is similar to classification, and the similarity and difference of data are divided according to big data. Data in the same category are very similar. In this study, after the learner analysis and resource analysis, learners with common interests and learning needs will be promoted through the principle of association clustering, and similar related learning resources will be promoted to college students to improve learning efficiency and effectiveness.

Ease of use: The push model in this study embodies the design idea of "learner-centered". 
Actively create an effective learning environment and atmosphere, attach importance to the guidance and help of online learning, and design an environment that can mobilize learners 'enthusiasm for autonomous learning, and pay attention to cultivating learners' cooperative learning ability. Whether it is the setting up of the online learning environment, the choice of online learning technology, the design of teaching and learning resources, the organization and implementation of activities, etc., all need to reflect good ease of use, users can quickly and conveniently apply. All these fully explain that the design of online resource push should reflect the learner-centered design concept.

Utility: The product's user experience can directly determine the success or failure of the product. Successful online resources must also have a successful user experience. To know whether the user experience of the online resource push model is good, a user experience analysis needs to be established.

Precision: Online learning plays an increasingly important role in the reform of higher education. As one of the means for college students to obtain information, online resources have been widely used. Based on the analysis of learners 'characteristics and resources' characteristics, the online resource push model is built in this study to realize the personalized resource push for different college students, which embodies the characteristics of the precision and demand of online resource push. For learners with different subject backgrounds, they can group and push what they are interested in to achieve personalized and customized point-to-point, point-to-point precise content push.

\subsection{Research Model Construction}

The construction of this research model is based on the aforementioned theories of association, multiple intelligence, humanism, etc.. According to the current situation and needs of college students, college teaching teachers, online resource production and management personnel, and detailed statistical analysis, combined with the design principles, design bases, design concepts, etc., with reference to relevant models, finally built a personalized online resource push model for college students. Learners based on big data and cloud computing and based on the association clustering principle, a hybrid, knowledge point as a unit online learning resource push model, which is learner-centered, Firstly, learner analysis using cloud computing, big data, etc.; Construct a personalized and intelligent learning environment based on the characteristics of learners and resources. The personalized learning resource push for college students is divided into four types: intelligent push; Proactive push; Manual push and mixed push. The process of these four types of push is analyzed in detail by means of semantic analysis. The model is divided into nine major elements: learner analysis; Personalized learning environment construction; Analysis of resource characteristics; Resource organization; Resource push strategy; Resource delivery platform; Resource push type; Resource delivery technology; Guarantee mechanism. The model adopts the principle of correlation clustering and takes college students as the center.

The related clustering principle of the model is embodied in: related clustering among various online learning resources; The related clustering among teachers, experts and learners; The related clustering between learners and other learners at home and abroad; Related clustering between resource platforms; Related clustering among online learning resources, learners, and online resource platforms.

The model is centered on learners: the ultimate goal of building the model is also to provide learners with the quality resources they really need to improve the online learning effect.

\section{Conclusions and Perspectives}

Personalized learning is based on the differences of learners, and with the support of advanced technology, flexible resource push methods are adopted to meet learners 'learning needs. This paper uses big data and cloud-related technologies, adopts the principle of related clustering, and constructs a two-feature analysis model based on the characteristics analysis of learners and resource characteristics analysis. And with the knowledge point as the unit to carry on the online 
learning resources personalized push, push the object for college students. The specific studies are as follows:

This paper makes a detailed investigation and analysis on the push status and demand of individual online learning resources for college students. This study introduces the present situation and needs of online learning resource delivery for college students, and makes a questionnaire and analyses the reliability of the questionnaire questions. A detailed questionnaire survey was conducted for college students, university teachers, resource production staff, resource management personnel, and resource delivery personnel. The investigation method combines network investigation with field investigation. The results of the survey are statistically analyzed, and finally the results of the current situation of online learning resource push and the needs of college students for online learning resources are obtained. It will lay the foundation for the next research on model element analysis and model construction.

This study adopts the principles of related clustering, using the theory of associative learning theory, multiple intelligence theory, personalized learning theory, humanistic learning theory, etc. as the theoretical guidance, using related technologies such as big data and cloud computing. A dual feature analysis model based on learner feature analysis and resource feature analysis is constructed. This model uses a variety of resource push methods, including intelligent push, active push, manual push and mixed push. Among them, artificial push is divided into three types: teacher push, expert push and peer push. The resource form of the push is based on the knowledge point to realize the personalized learning resource push for college students.

This study constructs a personalized online resource push model for college students, which includes nine elements. They are learner feature analysis, dynamic resource feature analysis, personalized, intelligent online learning environment design, resource organization form, resource push strategy, resource push platform, resource push type, resource push key technology, and resource push guarantee mechanism. This paper expounds the nine elements of the model in detail and provides a theoretical framework for the research of personalized online resource push.

\section{Acknowledgments}

This work was supported by the "Research on the Push of Personalized Online Learning Resources for College Students”(The 13th Five-Year Plan for Education Science in Jilin Province, GH180598) in part. The author would also like to thank the reviewers for their corrections and helpful suggestion.

\section{References}

[1] Luo Xingwen. Research on Personalized Distance Education System Based on Web Mining [J]. Computer Engineering and Design, 2007 (06);

[2] Chai Hongfu. Risk Report for Chinese Higher Vocational Colleges [J].Vocational and Technical Education, 2008 (06);

[3] Liao Yi. Support for Personalized Development of Network Learning Space Integration Design[J].Chinese Electrochemical Education,2014(09);

[4] Wang Wei. Related Data Application Research in the Library Field [J]. New Century Library, 2012(09).

[5] Zhao Fang. Research on Network Community Academic Resource Aggregation Model Based on Correlation Data[J].Library Science Research,2016(05);

[6] Wu Yonghe. Research on Web Content Filtering System Based on Chinese Network Educational Content Classification Standard [J].Electrochemical Education Research, 2006(10). 